\title{
Adsorbed xenon propellant storage: are nanoporous materials worth the weight?
}

\author{
Melanie T. Huynh', Nickolas Gantzler², Samuel Hough¹, David Roundy², Praveen K. \\ Thallapally ${ }^{3}$, and Cory M. Simon*1 \\ ${ }^{1}$ School of Chemical, Biological, and Environmental Engineering. Oregon State \\ University. Corvallis, OR. \\ ${ }^{2}$ Department of Physics. Oregon State University. Corvallis, OR. \\ ${ }^{3}$ Pacific Northwest National Laboratory. Richland, WA. \\ *Cory.Simon@oregonstate.edu
}

January 27,2021

\begin{abstract}
Xenon is used as a propellant for spacecraft. Conventionally, xenon is compressed to high pressures (75-300 bar) for bulk storage onboard the spacecraft. An adsorbed xenon storage system based on nanoporous materials (NPMs) could, potentially, (i) reduce the storage pressures, (ii) allow for thinner-walled and lighter pressure vessels, and (iii) if the NPM itself is sufficiently light, reduce the overall mass of the storage system and thus of the payload of the rocket launch.

To investigate, we develop a simple mathematical model of an adsorbed xenon storage system by coupling a mechanical model for the pressure vessel and a thermodynamic model for the density of xenon adsorbed in the NPM. From the model, we derive the optimal storage pressure, tailored to each NPM, with the objective of minimizing the mass of the storage materials (walls of the pressure vessel + NPM) required to store the xenon. The model enables us to: (i) rank NPMs for adsorbed xenon propellant storage, (ii) compare adsorbed storage to the baseline of bulk storage, and (iii) understand what properties of NPMs are desirable for adsorbed xenon propellant storage.

We use the model to evaluate several NPMs, mostly metal-organic frameworks (MOFs), for adsorbed xenon propellant storage at room temperature, using experimental xenon adsorption data as input. We find Ni-MOF-74 and MOF-505 outperform the traditional adsorbent, activated carbon. However, we find each optimized adsorbed xenon storage system is heavier than the optimized bulk storage system, owing dominantly to the large mass of the NPM itself. Our model suggests that, for a NPM to provide a lighter adsorbed xenon storage system compared to bulk storage, the saturation loading of xenon in the adsorbent must exceed ca. $94 \mathrm{mmol} \mathrm{Xe/g}$ adsorbent.
\end{abstract}




\section{Introduction}

Ion thrusters are used to propel spacecraft and satellites [1]2]. Xenon is commonly used as a propellant owing to its inertness, high molecular weight, and relatively low ionization energy [3].

To store xenon propellant onboard the spacecraft, xenon is typically compressed and stored at high pressures (75-300 bar) [4-7] between $20^{\circ} \mathrm{C}$ and $50^{\circ} \mathrm{C}$, in a supercritical state [8]. The pressure vessel must have thick walls to safely contain the xenon at these high pressures, making it heavy. Because the cost of launching a payload into Earth's orbit is ca. 10000 USD/lb [9], it is desirable to reduce the mass of storage materials required to store xenon propellant onboard spacecraft.

We investigate the feasibility of an alternative xenon storage strategy, with the objective of reducing the mass of the storage materials required to carry the xenon propellant into space: packing the pressure vessel with a porous adsorbent material to help densify the xenon (i.e, use an adsorbent in combination with pressurization). Activated carbon has been investigated for adsorbed xenon propellant storage, but it does not reduce the mass of the storage system [10]. Newer classes of nanoporous materials, such as metal-organic frameworks (MOFs) [11], porous organic cages (POCs) [12], and covalent organic frameworks (COFs) [13], exhibit very high internal surface areas [14 15] and have demonstrated promise for gas densification in the context of vehicular hydrogen and methane storage [16], motivating us to consider these advanced nanoporous materials for adsorbed xenon propellant storage. Moreover, several of these nanoporous materials exhibit a high affinity for xenon, evidenced by their adsorptive selectivity for xenon in the context of separations [17-20].

Here, we develop a simple mathematical model of an adsorbed xenon propellant storage system that enables us to evaluate and rank adsorbents for adsorbed xenon propellant storage. Our objective is to minimize the mass of storage materials required to carry the xenon propellant needed for the mission. For conventional, bulk xenon storage, the storage material is comprised of the material composing the walls of the pressure vessel. For adsorbed xenon storage, the storage materials

are comprised of the walls of the pressure vessel and the mass of the adsorbent material. Using our model, we find the optimal storage pressure that minimizes the mass of the storage materials, under both bulk and adsorbed xenon storage strategies. The optimized conventional, bulk storage system serves as a baseline for evaluating porous materials for adsorbed xenon storage.

Our hypothesis is that the optimal storage pressure for the adsorbed xenon storage system is lower than that of the bulk xenon storage system, thereby allowing for thinner-walled and thus lighter pressure vessels in the adsorbed storage system. The important question our model addresses is whether the reduced mass of the pressure vessel in the adsorbed xenon system compensates for the (added) mass of the adsorbent required to store the xenon at a lower pressure. The answer to this question depends on the xenon adsorption isotherm in and density of the nanoporous material. We assess several nanoporous materials for xenon propellant storage, using experimentally reported xenon adsorption isotherms as input to our model. We find that MOF-505 and Ni-MOF-74 outperform the traditional adsorbent, activated carbon. However, when comparing the adsorbed and bulk xenon storage systems, we find that none of the nanoporous materials considered compete with the bulk storage system in terms of reducing the overall mass of the storage system. 


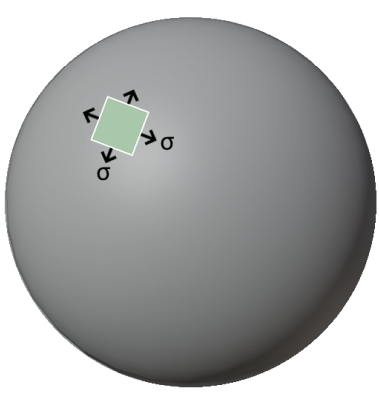

(a)
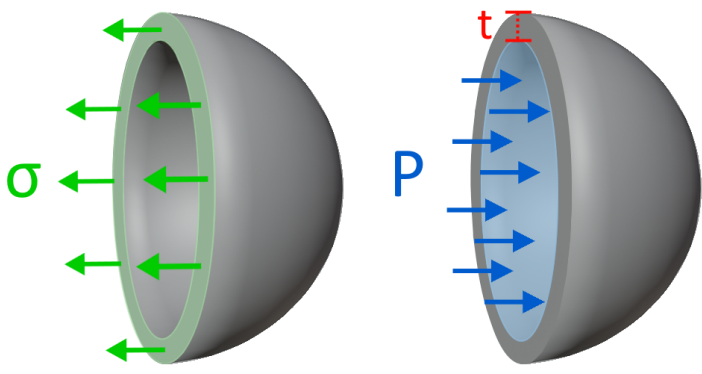

(b)

Figure 1: Thin-walled, spherical pressure vessel model. (a) A spherical pressure vessel (a shell of homogeneous material). A patch is shown on an arbitrary location, subject to biaxial stress $\sigma$. The stress $\sigma$ is internal to the material comprising the walls of the vessel and, under the thin-wall approximation, is spatially uniform within the material. (b) A static free-body diagram of half of the spherical pressure vessel, showing the circumferential stress $\sigma$ inside the walls, giving rise to a force that balances the force arising from the pressure $P$ exerted on the plane by the xenon fluid inside. The thickness of the wall of the vessel is $t$.

On the basis of a strong relationship between the adsorbent performance and its xenon adsorption properties, our model suggests that an adsorbent must exhibit a saturation loading of xenon that exceeds ca. $94 \mathrm{mmol}$ Xe/g adsorbent to outcompete a bulk storage system. We also find that nanoporous materials that exhibit high gravimetric surface areas tend to perform well for adsorbed xenon storage. Our conclusions rest on several simplifying assumptions, which we clearly list and discuss.

\section{Modeling the pressure vessel, bulk xenon density, and xenon adsorption in the adsorbent}

In this section, we formulate the mathematical models we use to describe the pressure vessel, bulk xenon gas, and xenon adsorption in the adsorbent. We later couple these models together to compose our models of both a bulk and adsorbed xenon propellant storage system.

\subsection{The pressure vessel: spherical and thin-walled}

Take the pressure vessel storing the xenon, in either the bulk or adsorbed phase, as a spherical shell composed of a homogeneous, elastic material. Let $r[\mathrm{~m}]$ be the inner radius of the shell and $t[\mathrm{~m}]$ be the (uniform) thickness of the vessel walls. Here, we relate the pressure $P$ [bar] of (bulk or adsorbed) xenon inside the vessel to the resulting circumferential stress $\sigma$ [bar] internal to the material composing the vessel walls. We use this relation to set the thickness of the walls of the vessel to safely contain the xenon without rupturing. 


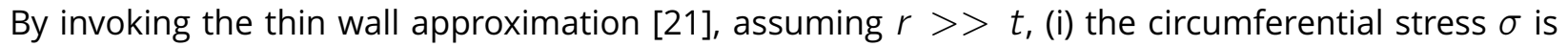
spatially uniform in the material and (ii) we do not distinguish between the inner and outer radius $r$. A free body diagram on a hemisphere of the vessel (see Fig. 1 balances two opposing forces in the direction normal to the plane on which the hemisphere sits, arising from: (a) the circumferential stress in the material and (b) the pressure of the gas on the inner walls, giving:

$$
P \pi r^{2}=\sigma 2 \pi r t
$$

We design the vessel by choosing the wall thickness $t$ such that the wall stress $\sigma$ is equal to $\beta \sigma_{y}$ where $\beta<1$ is a safety factor and $\sigma_{y}$ [bar] is the yield strength of the material composing the vessel walls:

$$
t=\frac{P r}{2 \beta \sigma_{y}} .
$$

We assume the vessel walls are composed of a titanium alloy (Ti-6Al-4V) commonly used for aerospace applications [22 23] with yield strength $\sigma_{y}=8250.0$ [bar] [23] and density $\rho_{v}=4429$ $\mathrm{kg} / \mathrm{m}^{3}$ [22]. N.b. mechanical properties of alloys could depend on whether they are under uniaxial or biaxial stress [24]. We use a safety factor $\beta=0.5$ as in Ref. [25].

\subsection{Density of bulk xenon fluid: interpolation of NIST data}

We interpolate data from the NIST Chemistry WebBook [26] to characterize the density of bulk xenon gas, $\rho_{X e}\left[\mathrm{~mol} / \mathrm{m}^{3}\right]$, as a function of pressure, $P$, at constant temperature, $T=298 \mathrm{~K}$. Fig. 2 displays $\rho_{X e}=\rho_{X e}(P ; T)$. Note that $298 \mathrm{~K}$ is above the critical temperature of xenon $\left(T_{c}=289.74 \mathrm{~K}\right)$. Near the critical pressure of xenon $\left(P_{c}=58.42\right.$ bar), small changes in pressure result in large changes in density.

For comparison, we also show the density of the ideal gas in Fig. 2. The ideal gas law is not sufficiently accurate for describing the density of xenon at high pressures relevant to propellant storage. As a result of attractions between the xenon particles, the xenon fluid exhibits a higher density than the ideal gas in the pressure range shown in Fig. 2 .

\subsection{Density of adsorbed xenon: the Langmuir adsorption model}

To describe the density of adsorbed xenon in a porous material, $\rho_{X e}^{\text {ads }}\left[\mathrm{mol} / \mathrm{m}^{3}\right]$, as a function of pressure and at fixed temperature, we use Langmuir's single-site equilibrium adsorption model [27]:

$$
\rho_{X e}^{\text {ads }}(P)=\rho_{\text {ads }} M \frac{K P}{1+K P}
$$

where $M$ [mol Xe/kg adsorbent] is the saturation loading of xenon in the adsorbent, $K$ [bar $\left.{ }^{-1}\right]$ is the Langmuir parameter, the inverse of the pressure at which half the adsorption sites are occupied and a metric of the affinity of xenon for the material, and $\rho_{a d s}\left[\mathrm{~kg} / \mathrm{m}^{3}\right]$ is the bulk density of the adsorbent (when devoid of gas); this makes $M \rho_{a d s}\left[\mathrm{~mol} / \mathrm{m}^{3}\right]$ the density of adsorption sites in the adsorbent. 


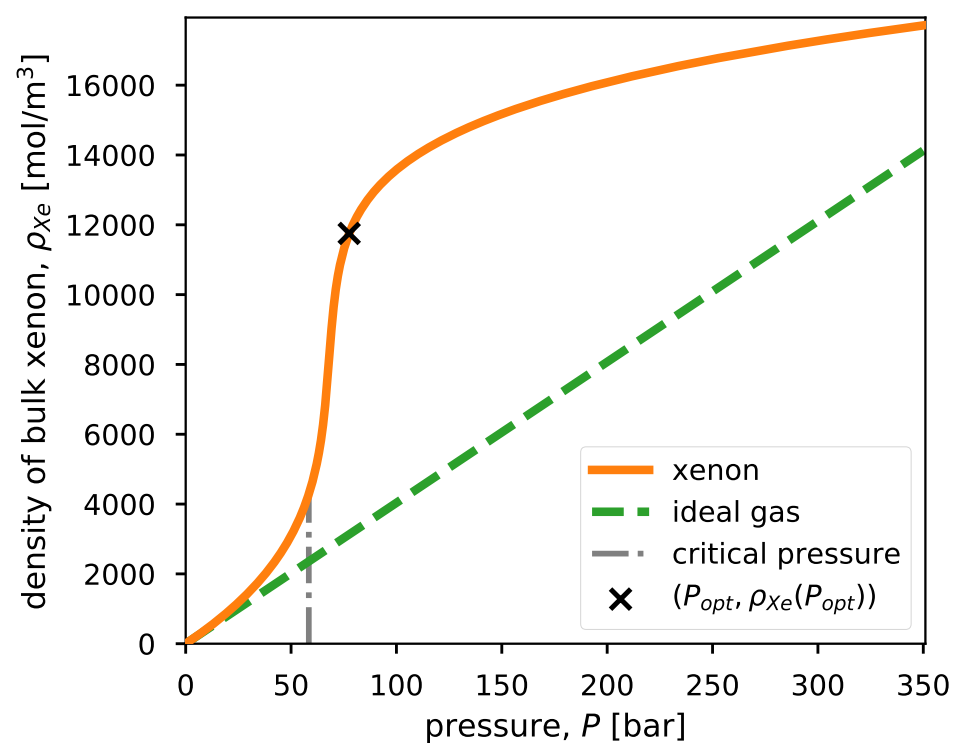

Figure 2: The density of xenon, $\rho_{X e}=\rho_{X e}(P)$, as a function of pressure, $P$, at a fixed temperature of $298 \mathrm{~K}$, taken from NIST [26]. For comparison, the density of the ideal gas is also shown. The vertical, dashed line marks the critical pressure of xenon $\left(T_{c}=289.74 \mathrm{~K}, P_{c}=58.42 \mathrm{bar}\right.$ ). The $\mathrm{x}$ marks the optimal storage conditions in a bulk xenon propellant storage system, which we will derive later.

For the purposes of modeling adsorbed xenon storage, under the single-site Langmuir model, a porous material is fully characterized by $M, K$ and $\rho_{\text {ads }}$. Volumetric $\left(\rho_{X e}^{\text {ads }}\right)$ and gravimetric $\left(\rho_{X e}^{\text {ads }} / \rho_{\text {ads }}\right)$ xenon adsorption in the material (gravimetric/volumetric with respect to the amount of the material, not the amount of gas), both of which are important for xenon propellant storage, are related by $\rho_{\text {ads }}$.

For each adsorbent material under consideration:

We identify its Langmuir model parameters $K$ and $M$ from its experimentally measured gravimetric xenon adsorption isotherm [mol Xe/kg adsorbent] in a least-square fitting routine. As opposed to interpolating the experimental adsorption isotherm data to characterize $\rho_{X e}^{\text {ads }}(P)$, as how we interpolate data to characterize the bulk xenon density $\rho_{X e}(P)$, the Langmuir model allows us to extrapolate the adsorbed density to larger pressures than observed in the experiments, which are up to only ca. 1 bar. We exclude adsorbents from our analysis whose adsorption isotherms did not exhibit a plateau, preventing reliable extrapolation of adsorption to higher pressures.

We approximate the bulk density $\rho_{\text {ads }}$ of the nanoporous materials as equal to the crystal density of the material, but revisit this assumption later for materials with reported bulk densities [28]. The bulk density is typically less than the crystal density owing to interstitial voids [28] and depends on the form of the material (powder, pellet, etc.) [29.31]. 
Table 1: Description of model parameters/variables.

$\begin{array}{clc}\text { symbol } & \text { description } & \text { units } \\ n_{X e} & \text { moles of xenon required for mission } & \mathrm{mol} \\ P & \text { pressure of xenon gas in the bulk- or adsorbed-storage vessel } & \mathrm{bar} \\ \rho_{X e} & \text { density of xenon gas in the bulk phase } & \mathrm{mol} / \mathrm{m}^{3} \\ \rho_{X e}^{\text {ads }} & \text { density of xenon gas in the adsorbent (absolute adsorption) } & \mathrm{mol} / \mathrm{m}^{3} \\ K & \text { Langmuir parameter of xenon in the adsorbent } & \mathrm{bar} \\ M & \text { saturation loading of xenon in the adsorbent (under Langmuir model) } & \mathrm{mol} \mathrm{Xe/kg} \mathrm{adsorbent} \\ \rho_{a d s} & \text { bulk density of the (empty) adsorbent } & \mathrm{kg} / \mathrm{m}^{3} \\ \rho_{V} & \text { density of the material composing the vessel walls } & \mathrm{kg} / \mathrm{m}^{3} \\ \sigma_{y} & \text { yield strength of material composing the vessel walls } & \mathrm{bar} \\ m_{v} & \text { mass of material composing the vessel walls } & \mathrm{kg} \\ m_{a d s} & \text { mass of adsorbent filling the vessel } & \mathrm{kg} \\ W_{X e} & \text { molar mass of xenon } & \mathrm{kg} / \mathrm{mol}\end{array}$

\section{Xenon storage}

We now couple the models for the xenon fluid, pressure vessel, and adsorbent to formulate a model for both bulk- and adsorbed-xenon storage systems. For both storage strategies, our first goal is to determine the mass of storage materials- the mass of material composing the walls of the pressure vessel and, if adsorbed-xenon storage, the mass of the adsorbent material- needed to carry the $n_{X e}$ [mol] of xenon required for the mission. The mass of storage materials required is a function of our choice of storage pressure. Our second goal is to then find the storage pressure, for both bulkand adsorbed-xenon propellant storage systems, that minimizes the mass of storage materials. The primary performance metric of a given xenon propellant storage system is the tankage fraction: the mass of storage materials required per mass of xenon propellant we wish to store [25].

\subsection{Bulk xenon propellant storage}

In bulk xenon storage, we compress the pure xenon fluid and contain it in a free-space, spherical pressure vessel.

The volume of the vessel required ${ }^{\star}$ to store the $n_{X e}[\mathrm{~mol}]$ of xenon is $n_{X e} / \rho_{X e}$. Thus, the radius of the spherical vessel as a function of storage pressure is:

$$
r=r(P)=\left(\frac{3}{4 \pi} \frac{n_{X e}}{\rho_{X e}(P)}\right)^{1 / 3} .
$$

Substituting $r(P)$ into the stress model for the vessel in eqn. 2. we arrive at the required thickness of the vessel, $t=t(P)$, to safely contain the compressed xenon. Finally, the mass of material comprising the walls of the pressure vessel is, after (conceptually) flattening the vessel walls:

$$
m_{v}=4 \pi r^{2} t \rho_{v}=m_{v}(P)=\frac{3 n_{X e} \rho_{v} P}{2 \beta \sigma_{y} \rho_{X e}(P)},
$$

\footnotetext{
${ }^{*}$ Recall, under the thin-walled vessel approximation, we do not distinguish between an outer- and inner-volume.
} 
where $\rho_{v}$ is the density of the material composing the vessel walls. Intuitively, $m_{v}$ scales with the density of the material composing the walls of the vessel, $\rho_{v}$, and with the required amount of xenon for the mission, $n_{X e}$. On the other hand, $m_{V}$ scales inversely with the yield stress of the vessel material, $\sigma_{y}$.

\subsubsection{Optimizing the storage pressure}

The optimal storage pressure $P_{o p t}[\mathrm{bar}]$ minimizes the material composing the vessel walls that is required to safely contain the $n_{X e}[\mathrm{~mol}]$ xenon for the mission:

$$
P_{o p t}=\underset{P}{\arg \min }\left[m_{v}(P)\right]
$$

We minimize $m_{v}(P)$ numerically to find $P_{\text {opt }}$ The associated tankage fraction of the optimized bulkstorage vessel is $m_{v}\left(P_{o p t}\right) /\left(n_{X e} w_{X e}\right)$, with $w_{X e}$ the molar mass of xenon.

\subsection{Adsorbed xenon propellant storage}

In adsorbed xenon storage, we fully pack the spherical pressure vessel with porous material to store xenon gas in the adsorbed phase.

The mass of adsorbent $m_{a d s}$ needed for the mission, as a function of storage pressure, $P$, is

$$
m_{a d s}=m_{a d s}(P)=\frac{\rho_{a d s} n_{X e}}{\rho_{X e}^{a d s}(P)}
$$

with the density of adsorbed xenon, $\rho_{X e}^{\text {ads }}$, given by the Langmuir adsorption model in eqn. 3 . Imposing the volume of the vessel to be equal to the volume of the adsorbent required, the radius of the spherical pressure vessel is:

$$
r=r(P)=\left(\frac{3}{4 \pi} \frac{n_{X e}}{\rho_{X e}^{\text {ads }}(P)}\right)^{1 / 3}
$$

which is eqn. 4 with the bulk xenon density replaced with the adsorbed xenon density.

The required thickness of the vessel walls, $t=t(P)$, follows from substituting $r(P)$ into the stress model for the vessel in eqn. 2. Finally, the mass of material composing the walls of the pressure vessel is:

$$
m_{v}=4 \pi r^{2} t \rho_{v}=m_{v}(P)=\frac{3 n_{X e} \rho_{v} P}{2 \beta \sigma_{y} \rho_{X e}^{a d s}(P)},
$$

which is eqn. 5 with the bulk xenon density replaced with the adsorbed xenon density.

\subsection{1 optimizing the storage pressure}

The storage pressure that minimizes the total mass of storage materials required to carry the xenon for the mission is found analytically (setting the derivative equal to zero):

$$
P_{o p t}:=\underset{P}{\arg \min }\left[m_{a d s}(P)+m_{v}(P)\right]=\sqrt{\frac{2 \beta \sigma_{y} \rho_{a d s}}{3 K \rho_{v}}} .
$$


This optimum storage pressure balances the mass of the adsorbent required, which decreases with increasing pressure, and the mass of the vessel walls required to contain the pressure. Intuitively, the optimal storage pressure is low when using porous materials that adsorb xenon strongly (large $K)$ and high if the porous material is very dense (large $\rho_{\text {ads }}$ ) or if the vessel walls have a high yield strength (large $\sigma_{y}$ ).

Finally, the minimal mass of storage materials required for the mission is $m_{\text {ads }}\left(P_{\text {opt }}\right)+m_{v}\left(P_{\text {opt }}\right)$. The optimal tankage fraction is then:

$$
\frac{m_{a d s}\left(P_{o p t}\right)+m_{v}\left(P_{o p t}\right)}{n_{X e} W_{X e}}=\frac{1}{M \rho_{a d s} W_{X e}}\left(\sqrt{\rho_{a d s}}+\sqrt{\frac{3 \rho_{v}}{2 \sigma_{y} \beta K}}\right)^{2} .
$$

The effects of material properties on the tankage fraction are apparent: to provide a small tankage fraction, we wish for:

the material composing the vessel walls to be light (small $\rho_{v}$ ) and strong (large $\sigma_{y}$ ).

the adsorbent material to be light (small $\rho_{\text {ads }}$ ), strongly adsorb xenon (large $K$ ), and have a large number of xenon adsorption sites packed per volume (large $M \rho_{\text {ads }}$ ). Note that the first and last wishes compete.

While these effects of material parameters on the tankage fraction are qualitatively unsurprising, eqn. 11 allows us to quantitatively evaluate several adsorbents for adsorbed xenon propellant storage and compare to the bulk storage strategy.

\subsection{Remarks}

Conveniently, the optimal storage pressure and tankage fraction do not depend on the amount of xenon required for the mission, $n_{X e}$, for both bulk and adsorbed storage systems (see eqn. 5 and eqns. 10 and 11 respectively). However, the choice of the safety factor $\beta$ does affect our results. First, the ranking of adsorbents according to their optimal tankage fractions could conceivably change with $\beta$ (see eqn. 11). Second, the ratio of the optimal tankage fractions for bulk and adsorbed storage systems depends on $\beta$ (divide eqn. 5 by eqn. 11 ).

Eqn. 11 shows the effects of material parameters on the optimal tankage fraction, but bear in mind that these material parameters are intimately coupled and correlated, and therefore cannot be independently tuned. For example, denser materials tend to more strongly attract xenon, giving rise to a positive correlation between $\rho_{a d s}$ and $K$.

\section{Results}

We now evaluate several porous materials for adsorbed xenon propellant storage, with bulk xenon storage as a baseline. The data and Julia code to fully reproduce our calculations and plots are available at github.com/SimonEnsemble/PropellantStorage.

Without loss of generalization, we take the required mass of propellant needed for the mission as $n_{X e} W_{X e}=100 \mathrm{~kg}$. 

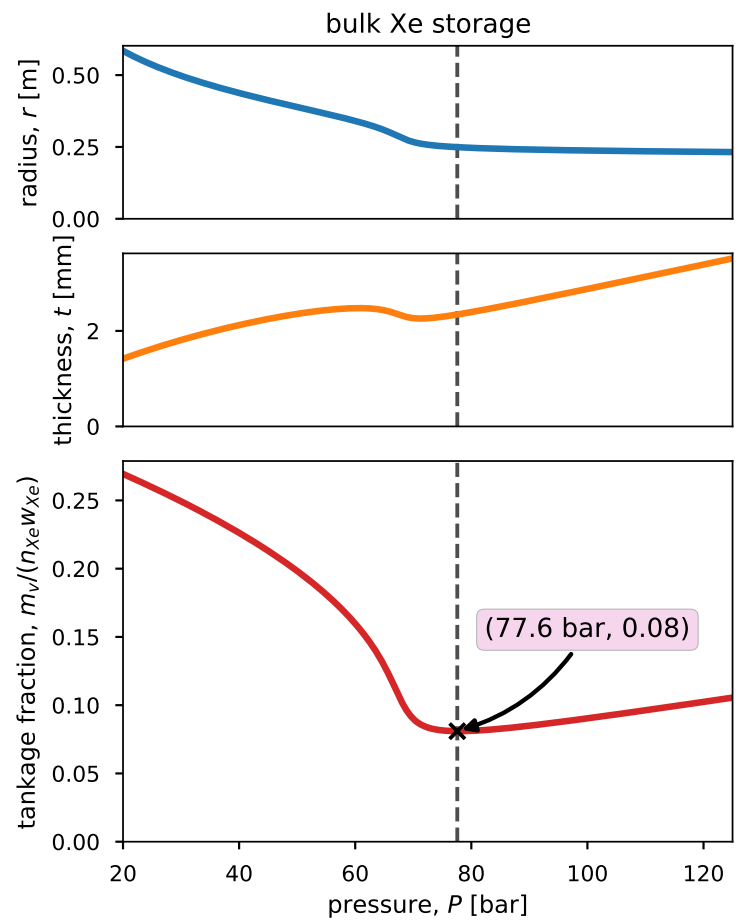

Figure 3: Optimizing the compressed, bulk xenon storage system at $298 \mathrm{~K}$. The radius of the vessel, the thickness of its walls, and the tankage fraction are shown as a function of the storage pressure. The optimal storage pressure (vertical, dashed line) minimizes the tankage fraction.

\subsection{Compressed, bulk xenon storage}

As a baseline, we first analyze a bulk xenon storage system, where xenon gas is compressed and stored in a spherical, thin-walled pressure vessel, without an adsorbent.

Fig. 3 shows the radius, wall thickness, and tankage fraction for bulk xenon storage over a pressure range of 20 bar to 125 bar. The optimal storage pressure is $P_{o p t}=77.6$ bar, which provides a minimal tankage fraction of $m_{v}\left(P_{o p t}\right) /\left(n_{X e} w_{X e}\right)=0.08$. Notably, $P_{o p t}>P_{c}$ to exploit the large slope of $\rho_{X e}(P)$ in Fig. 2 where a small change in pressure results in a large change in xenon density. See the $\mathrm{x}$ in Fig. 2 that marks $\left(P_{o p t}, \rho_{X e}\left(P_{o p t}\right)\right)$.

\subsection{Adsorbed xenon storage}

Next, we evaluate the performance of several porous materials for adsorbed xenon propellant storage. We not only rank the performance of the adsorbents, but also compare the performance of the adsorbed xenon storage systems with the bulk storage system.

\subsubsection{The porous material candidates}

As candidate nanoporous material adsorbents for adsorbed xenon propellant storage, we consider the MOFs, SBMOF-1 [32], Ni-MOF-74 [33], HKUST-1 [34], SBMOF-2 [35], Co $(\mathrm{HCOO})_{6}$ [36], MOF-505 


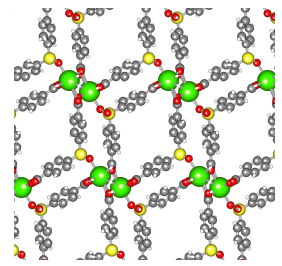

SBMOF-1

$\rho_{\text {ads }}=1570 \mathrm{~kg} / \mathrm{m}^{3}$

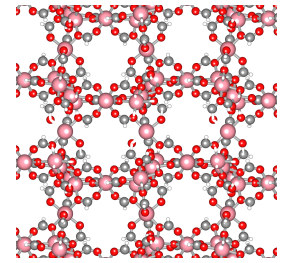

$\mathrm{CO}_{3}(\mathrm{HCOO})_{6}$

$\rho_{\text {ads }}=1822 \mathrm{~kg} / \mathrm{m}^{3}$

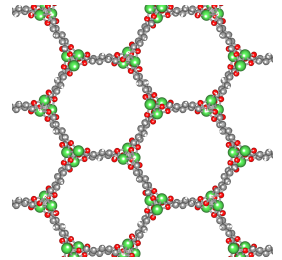

Ni-MOF-74

$\rho_{\text {ads }}=1194 \mathrm{~kg} / \mathrm{m}^{3}$

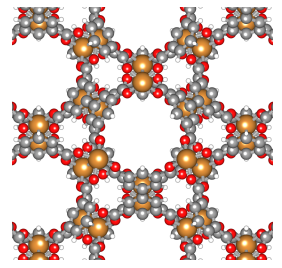

MOF-505

$\rho_{\text {ads }}=927 \mathrm{~kg} / \mathrm{m}^{3}$

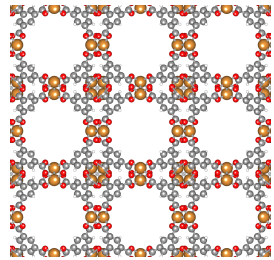

HKUST-1

$\rho_{\text {ads }}=879 \mathrm{~kg} / \mathrm{m}^{3}$

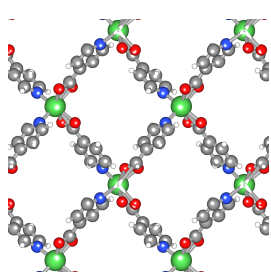

$\mathrm{Ni}(\mathrm{PyC})_{2}$

$\rho_{\text {ads }}=1250 \mathrm{~kg} / \mathrm{m}^{3}$

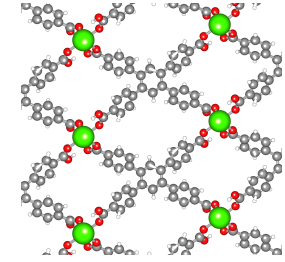

SBMOF-2

$\rho_{\text {ads }}=1192 \mathrm{~kg} / \mathrm{m}^{3}$

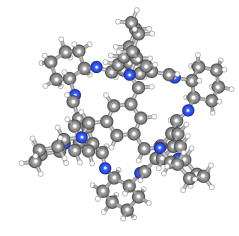

CC3

$\rho_{\text {ads }}=9589 \mathrm{~kg} / \mathrm{m}^{3}$

Figure 4: The crystal structures of the nanoporous material candidates we consider for adsorbed xenon propellant storage and their (crystal) densities, $\rho_{a d s}$. For CC3, a molecular material, we show only a single cage.

[37] (=NOTT-100 [38]), and $\mathrm{Ni}(\mathrm{PyC})_{2}$ [39] and POC material CC3 [40]. We also consider activated carbon as a baseline. We selected these materials because their experimentally measured xenon adsorption isotherms near $298 \mathrm{~K}$ are available in the literature [17, $35,39,41-44]$. Fig. 4 displays the crystal structures of the candidate nanoporous materials and their crystal densities $\left(=\rho_{\text {ads }}\right)$. For activated carbon, which is amorphous, we took the density as that of $1230 \mathrm{C}$ coconut shell activated carbon, used in Ref. [44], from the data sheet in Ref. [45], 500 kg/m³.

\subsubsection{The adsorbed xenon density in each porous material}

We use the Langmuir adsorption model $\rho_{X e}^{\text {ads }}(P)$ in eqn. 3 to describe the adsorbed density of xenon in each material as a function of pressure. We identify the Langmuir parameters $M$ and $K$ for each adsorbent by fitting $\rho_{X e}^{\text {ads }}(P) / \rho_{\text {ads }}$ to the experimentally measured, gravimetric (per mass of adsorbent) xenon adsorption data at $298 \mathrm{~K}$ (with the exception of MOF-505, $292 \mathrm{~K}$ and Ni-MOF74, $297 \mathrm{~K}$ ). Fig. S1 shows the raw gravimetric xenon adsorption data and the gravimetric Langmuir model fits, all of which reasonably describe the shape formed by the data. Tab. 2 lists the identified Langmuir parameters $M$ and $K$ for each adsorbent, in addition to the references for the adsorption data. Finally, Fig. 5 a displays (i) the volumetric (per volume of adsorbent) xenon adsorption data, converted from the gravimetric adsorption data using $\rho_{\text {ads }}$, (ii) the fitted models for the adsorbed xenon density, $\rho_{X e}^{\text {ads }}(P)$, and (iii) the bulk gas density $\rho_{X e}(P)$. The plot shows a larger pressure range than Fig. S1, on a logarithmic scale, to see how the model $\rho_{\text {ads }}$ extrapolates to pressures larger than found in the data. Compared with the bulk xenon density at the same temperature and pressure, adsorbents achieve a much higher xenon density at lower pressures (c.a. < 40 bar), but, at higher pressures, the bulk density is greater because the skeleton of the adsorbent occupies a fraction of the space and excludes xenon adsorbates. 


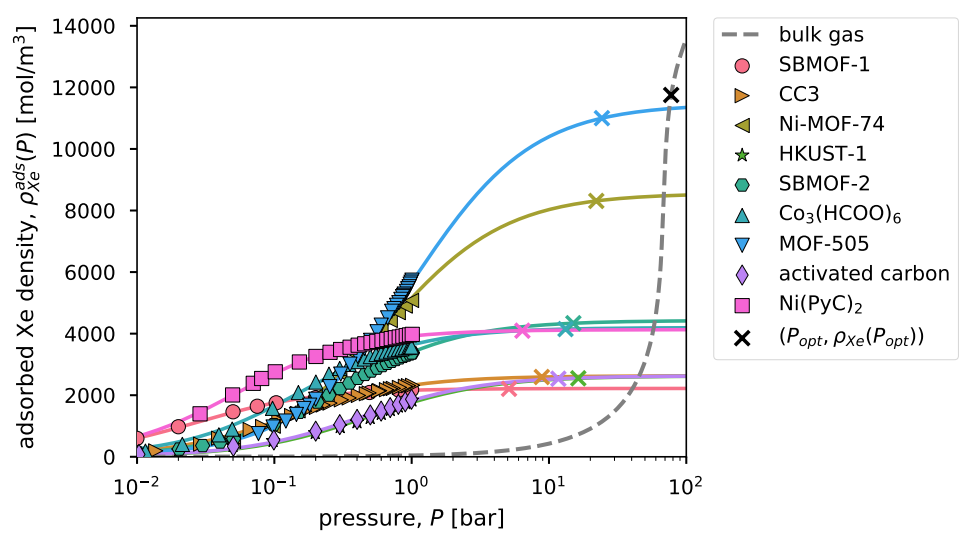

(a)

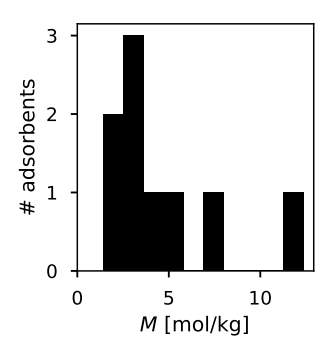

SBMOF-1

$\triangle \mathrm{CC} 3$

Ni-MOF-74

* HKUST-1

SBMOF-2

$\mathrm{Co}_{3}(\mathrm{HCOO})_{6}$

MOF-505

activated carbon

$\mathrm{Ni}(\mathrm{PyC})_{2}$
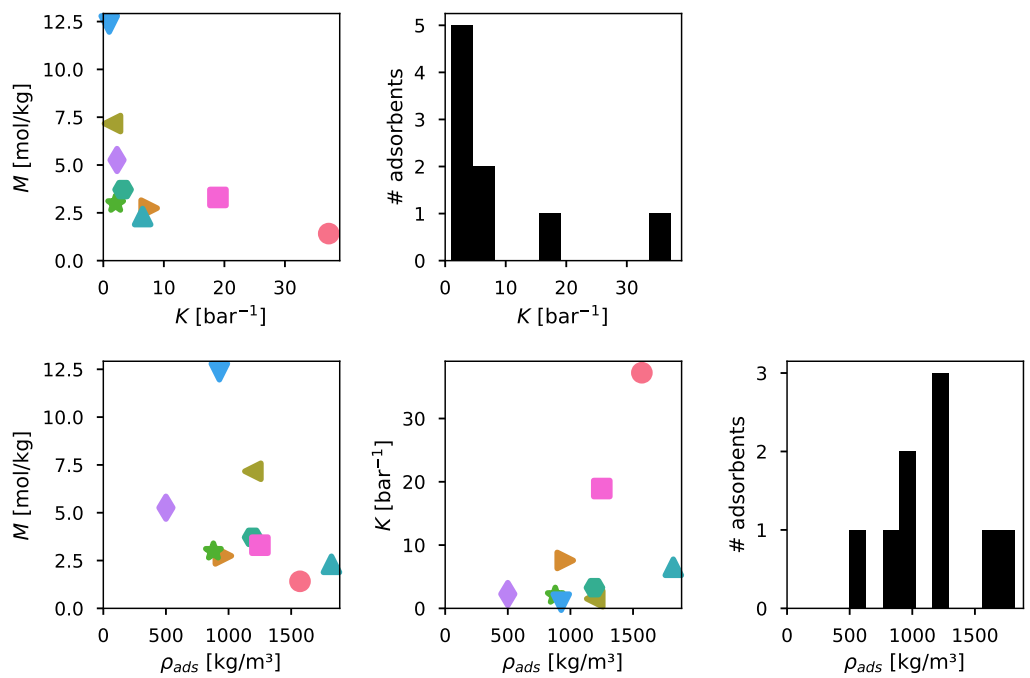

(b)

Figure 5: Xenon adsorption in the candidate adsorbents. (a) Curves show the fitted Langmuir adsorption model, $\rho_{X e}^{\text {ads }}(P)$ in eqn. 3 to describe the adsorbed xenon density in each adsorbent at $298 \mathrm{~K}$. Points show the experimentally measured xenon adsorption isotherms (at $298 \mathrm{~K}$, except for MOF-505, $292 \mathrm{~K}$, and Ni-MOF-74, $297 \mathrm{~K}$ ), converted from the raw gravimetric adsorption data using $\rho_{\text {ads }}$. The dashed curve shows the density of the bulk gas, $\rho_{X e}(P)$. The x's mark the optimal storage conditions $\left(P_{o p t}, \rho_{X e}^{\text {ads }}\left(P_{o p t}\right)\right)$ that we will derive later. (b) The distributions (diagonal) and correlations between (off-diagonal) the Langmuir $M$, Langmuir $K$, and density $\rho_{\text {ads }}$ that fully characterize the adsorbents in our model adsorbed xenon propellant storage system. 
Table 2: The identified Langmuir model parameters in the candidate materials.

\begin{tabular}{cccc} 
material & $\mathrm{M}[\mathrm{mol} \mathrm{Xe/kg]}$ & $\left.\mathrm{K}^{\mathrm{b}} \mathrm{bar}^{-1}\right]$ & reference for adsorption data \\
\hline SBMOF-1 & 1.41 & 37.2 & {$[17]$} \\
CC3 & 2.74 & 7.57 & {$[43]$} \\
Ni-MOF-74 & 7.17 & 1.52 & {$[17]$} \\
HKUST-1 & 2.99 & 2.04 & {$[17]$} \\
SBMOF-2 & 3.71 & 3.27 & {$[35]$} \\
O $_{3}(\mathrm{HCOO})_{6}$ & 2.30 & 6.50 & $[4]]$ \\
MOF-505 & 12.37 & 0.98 & {$[42]$} \\
Activated-Carbon & 5.26 & 2.26 & {$[4]$} \\
Ni(PyC $)_{2}$ & 3.30 & 18.9 & {$[39]$}
\end{tabular}

Although xenon adsorption data was also available for IRMOF-1 [46] and PCN-12 [42], we omit these MOFs from our analysis because their xenon adsorption isotherms do not exhibit a plateau, preventing reliable estimation of $M$ to extrapolate the adsorbed xenon density beyond the maximum pressure observed in the data, ca. 1 bar.

To summarize the properties of the adsorbents that dictate their performance for adsorbed xenon propellant storage, Fig. $5 \mathrm{~b}$ displays the distributions and correlations between the adsorbent parameters $K, M$, and $\rho_{\text {ads }}$.

\subsubsection{Optimizing the adsorbed-xenon storage system for each material}

For each adsorbent, we find the optimal storage pressure, $P_{\text {opt }}$ in eqn. 10 and the associated optimal tankage fraction, given in eqn. 11. Fig. 6a summarizes the performance of the materials for adsorbed xenon propellant storage, with the aim of minimizing the mass of storage materials required to carry the xenon propellant into space. The x's in Fig. $5 a$ mark $\left(P_{o p t}, \rho_{X e}^{\text {ads }}\left(P_{o p t}\right)\right)$ for each adsorbent.

Ranking the adsorbents. The adsorbents in Fig. $6 \mathrm{~b}$ are ranked by the optimal tankage fraction. Ni-MOF-74 and MOF-505 provide lower tankage fractions than an adsorbed xenon storage system based on the traditional adsorbent, activated carbon.

Bulk vs. adsorbed xenon storage. The optimal storage pressures for the adsorbed xenon storage systems are lower than for the bulk storage system; however, the optimal tankage fractions of the adsorbed storage systems are larger. Fig. 6b shows, with the bulk storage system as a baseline, the adsorbents reduce the mass of the vessel walls required to store the xenon, but at the expense of (i) achieving a lower density of xenon, resulting in a larger pressure vessel and (ii) carrying a large mass of adsorbent material. In conclusion, according to our mathematical model, the adsorbents provide a reduction (compared to bulk storage) in the mass of the vessel walls, owing to reduced storage pressures, but this does not compensate for the (additional) mass of the adsorbent material itself; for each adsorbent, the mass of the storage materials (vessel walls + adsorbent) required to 
carry the xenon into space is greater than the mass of the storage materials (vessel walls) for the bulk storage system.

\subsubsection{Relationship between performance and adsorption properties}

What properties of an adsorbent are desirable for xenon propellant storage? Addressing this question could lead to improved adsorbents that yield an adsorbed xenon storage system with a lower tankage fraction than bulk storage. While eqn. 11 provides insights into how $K, M$, and $\rho_{\text {ads }}$ influence the optimal tankage fraction, these parameters are in practice not independent, but correlated. For example, denser materials tend to offer a stronger interaction with xenon but a lower saturation loading (see Fig. 5b).

The saturation loading, $M$, of the adsorbent is a strong predictor of the optimal tankage fraction of the adsorbed xenon storage system. See Fig. 7. Eqn. 11 provides an explanation, by noting the tendency for (i) the mass of the adsorbent to dominate the optimal tankage fraction (see Fig. 6b) and (ii) $K P_{\text {opt }}>>1$, giving the approximation to the optimal tankage fraction:

$$
\frac{m_{a d s}\left(P_{o p t}\right)+m_{v}\left(P_{o p t}\right)}{n_{X e} w_{X e}} \approx \frac{m_{a d s}\left(P_{o p t}\right)}{n_{X e} W_{X e}}=\frac{1}{M w_{X e}}\left(1+\frac{1}{K P_{o p t}}\right) \approx \frac{1}{M w_{X e}} .
$$

This approximation is shown as the curve in Fig. 7. along which the data approximately lie. So, the performance of an adsorbent for adsorbed xenon propellant storage tends to be determined by, to first order, its saturation loading, $M$. This result is intuitive because (i) the optimal storage pressure tends to be near saturation conditions ( $K P_{o p t}>>1$ ), (ii) we wish to minimize the mass of storage materials, dominated by the adsorbent, and (iii) $M$ is the amount of Xe stored per mass of adsorbent at saturation conditions.

We use the approximation in eqn. 12 to estimate that, for an adsorbed storage system to give a lower optimal tankage fraction than the bulk storage system, the saturation loading of xenon in the

adsorbent must exceed $94 \mathrm{~mol} \mathrm{Xe/kg}$ adsorbent. Based on the relationship between $M$ and $\rho_{\text {ads }}$ in Fig. $5 b$ such an adsorbent must not be dense. Lighter adsorbents (lower $\rho_{\text {ads }}$ ) also tend to give adsorbed Xe storage systems with lower optimal tankage fractions; see Fig. $\mathrm{S2}$.

We also investigate the relationship between the optimized tankage fraction of the adsorbed xenon storage systems and the gravimetric surface area (defined by the zero potential energy contour of a xenon probe adsorbate in the pores, computed in iRASPA [47]) of the corresponding nanoporous materials. Fig. $\mathrm{S3}$ shows that nanoporous materials that exhibit high gravimetric surface areas tend to have lower tankage fractions. Similarly, according to virtual screenings of MOFs, for hydrogen storage, MOFs with the highest gravimetric surface areas tend to give the highest usable capacity of hydrogen [48]; however, for methane storage, intermediate gravimetric surface areas are desirable [49].

\section{Limitations}

Our mathematical model and the conclusions we extract from it are subject to several limitations emanating from simplifying model assumptions. We discuss some of these below. 


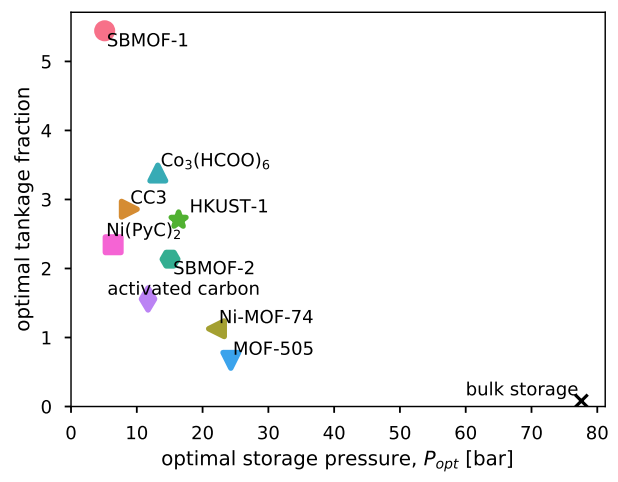

(a)

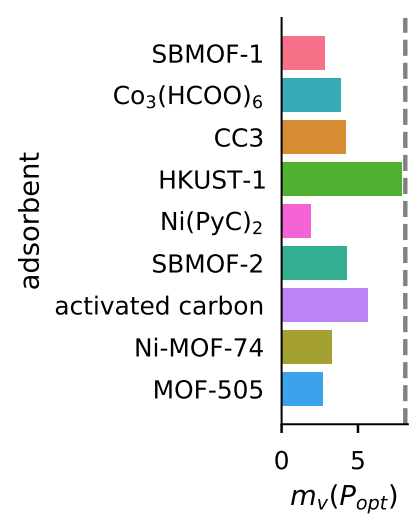

$[\mathrm{kg}]$

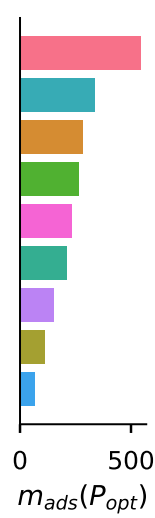

$[\mathrm{kg}]$

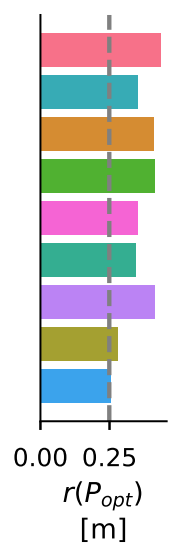

(b)

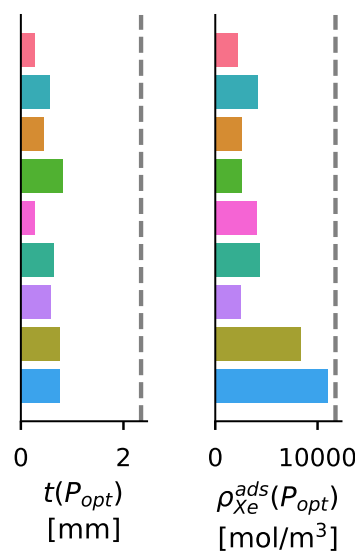

$\left[\mathrm{mol} / \mathrm{m}^{3}\right]$

Figure 6: Performance of the optimized adsorbed xenon propellant storage systems. (a) The optimal storage pressure $P_{o p t}$ and associated optimum tankage fraction for each adsorbent. As a baseline, the bulk storage system is depicted by the $\mathrm{x}$. (b) The mass of the pressure vessel walls, mass of adsorbent material, radius of the vessel, thickness of the vessel walls, and density of adsorbed xenon for each adsorbent. The horizontal dashed lines show the corresponding for the optimized bulk storage system. 


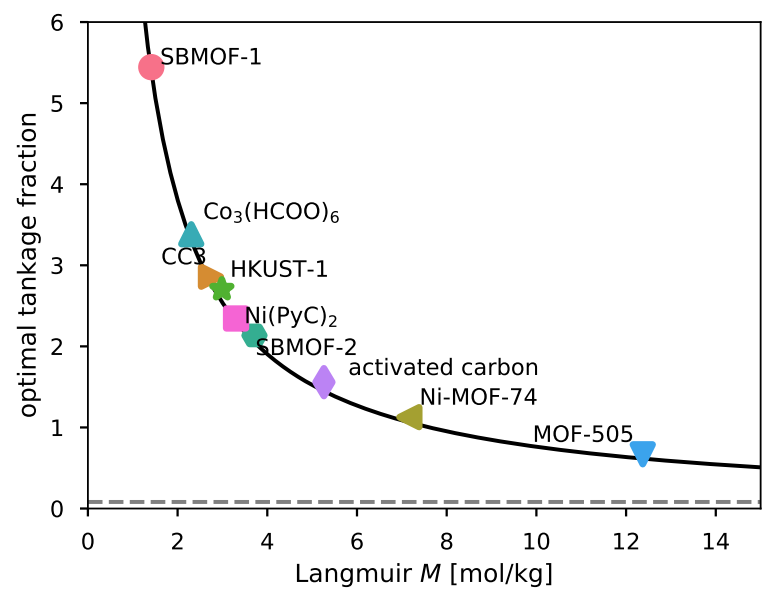

Figure 7: The relationship between the tankage fraction of each optimized adsorbed xenon storage system and the saturation loading of xenon in the adsorbent, $M$. The solid curve shows the approximation to the optimal tankage fraction in eqn. 12 .

The safety factor. The choice of the safety factor influences the comparison between adsorbents and between adsorbed and bulk storage systems (see eqns. 5 and 11 because it scales the contribution to the tankage fraction by the metal composing the vessel walls. We crudely investigated the sensitivity of our results to $\beta$ : only when $\beta \approx 0.05$ does the tankage fraction of MOF-505 compete with the bulk storage system. For this very low $\beta$, only CC3 and HKUST-1 switch rankings, indicating the ranking of adsorbents here is insensitive to the choice of the safety factor $\beta$.

Extrapolation of data on adsorbed xenon density in the nanoporous materials. Experimental xenon adsorption isotherm measurements were available in the adsorbents only up to ca. 1 bar (see Fig. S1). We fitted the Langmuir adsorption model to this data, then used the Langmuir model to, essentially, extrapolate the adsorption data to pressures much higher than 1 bar. See Fig. 5 a, Though we excluded nanoporous materials from our study whose adsorption isotherm data did not exhibit a plateau for reliable estimation of $M$, this extrapolation could still introduce significant error.

Bulk vs. crystal density of the nanoporous materials. To obtain the adsorbed xenon density [amount of gas per volume of adsorbent] in MOFs for gas storage applications, the measured gravimetric adsorption [amount of gas per mass of adsorbent] is multiplied by the density of the material [28 50]. We did so in eqn. 3 and Fig. 5a. using $\rho_{\text {ads }}$, taken to be equal to the crystal density. While the crystal density is often used for this conversion, in practice, adsorbents are compacted powders such as granules or pellets [29-31]. The density of such MOF powders is usually lower than the crystal density owing to interstitial voids [28]. That is, the density of the adsorbent packed into the vessel will differ from the crystal density [28 30].

We now investigate how our approximation, bulk density of the nanoporous material $\rho_{\text {ads }} \approx$ crystal density, influences our results. This is important because, in our model, $\rho_{\text {ads }}$ is used for two purposes: (1) converting the gravimetric adsorption data in the nanoporous materials to volumetric 


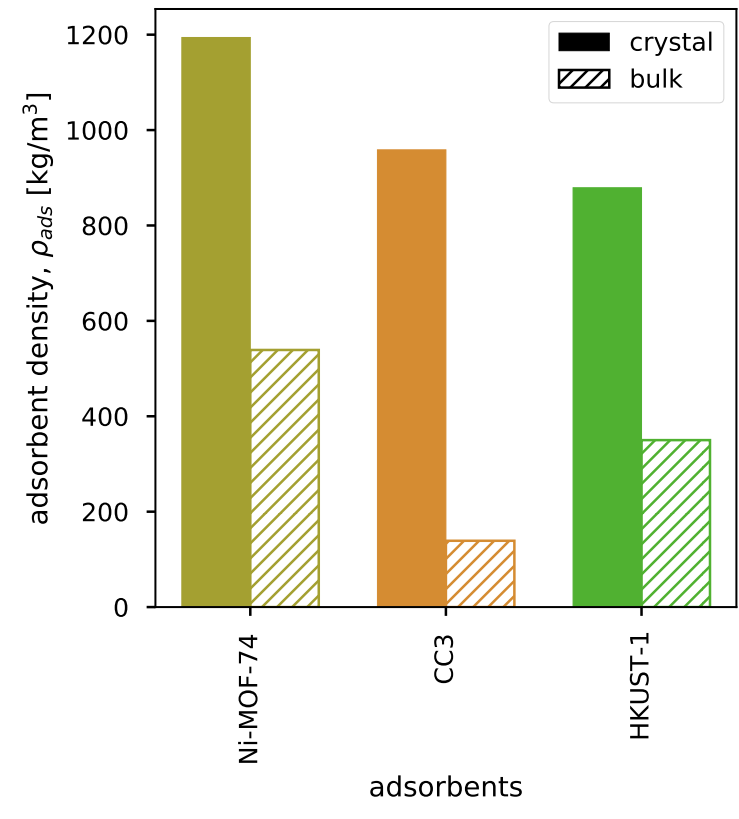

(a)

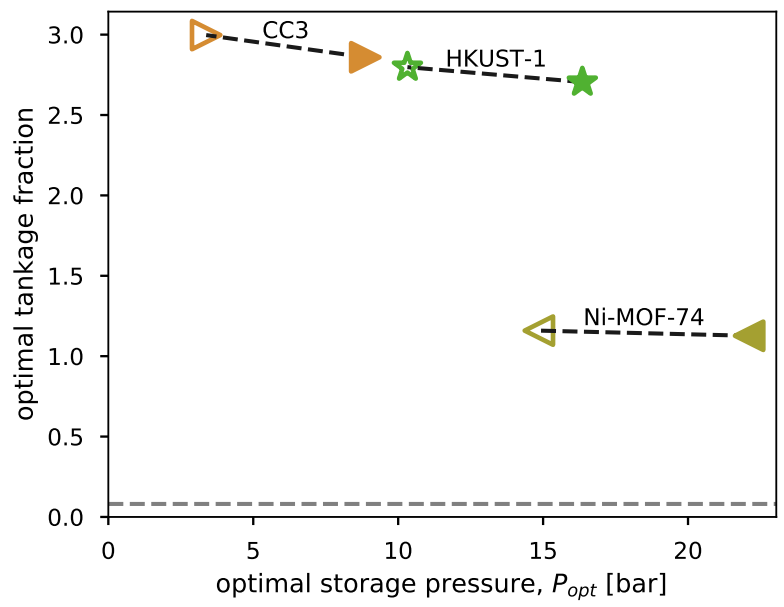

(b)

Figure 8: Investigating the impact of the approximation that the bulk density of the nanoporous material, $\rho_{a d s}$, is equal to the crystal density. (a) A comparison of the crystal density and measured bulk/tap density [28] of CC3, HKUST-1, and Ni-MOF-74. (b) The optimal tankage fraction and storage pressure of an adsorbed xenon storage system using CC3, HKUST-1, and Ni-MOF-74, using the bulk [hollow symbols] vs. crystal density [solid symbols] as input to the model.

adsorption to obtain $\rho_{X e}^{\text {ads }}(P)$ via eqn. 3 and (2) determining the mass of the adsorbent filling the pressure vessel $m_{a d s}$ in eqn.7.

The measured bulk/tap densities of CC3, HKUST-1, and Ni-MOF-74 reported in Ref. [28] are shown in Fig. 8a. We now use these bulk/tap densities for $\rho_{a d s}$ to investigate how the tankage fraction changes, compared to when we used the crystal density for $\rho_{\text {ads }}$ (listed in Fig. 4 as in Fig. 6a. Fig. 8b shows that, for these three materials for which the bulk density was available: when using the more realistic bulk density $\rho_{\text {ads }}$ as input to the model, the optimal storage pressures are reduced, but, the tankage fraction changes only marginally. I.e., the approximation bulk density $\approx$ crystal density is unlikely to significantly influence our conclusion that the adsorbed storage systems we considered do not provide lower tankage fractions than a bulk storage system.

The paucity of material space sampled. We only considered the eight nanoporous materials in Fig. 4 owing to a paucity of experimentally measured xenon adsorption isotherms for input to our model. Fig. $5 \mathrm{~b}$ displays the diversity of the material parameters $\left\{M, K, \rho_{\text {ads }}\right\}$ among this set of materials. There are thousands of additional exiting MOFs [51] that could, possibly, provide a lower tankage fraction than the bulk storage system. 
Thin-wall approximation for the pressure vessel. We invoked the thin-wall approximation to determine the thickness of the walls of the pressure vessel via eqn. 2. Fig. 3 shows that, indeed, $r \gg t$, making this approximation reasonable.

Geometry of the pressure vessel. We took the pressure vessel to be a sphere. Different pressure vessel geometries will require a different mechanical model to determine the mass of vessel material needed to safely contain the xenon.

A pressure vessel composed of a titanium alloy. For a simple estimate, we took the pressure vessel as composed of a titanium alloy. In practice, composite overwrapped pressure vessels (COPVs) are typically used for xenon propellant storage. In a COPV, a gas-impermeable, metallic inner-liner is overwrapped with a strong, permeable carbon fiber overwrap such as Kevlar. The partnership between these materials could allow for a lighter pressure vessel. [52, 53]

Residual gas in the adsorbent. A consideration for adsorbed gas storage is the residual gas trapped in the adsorbent at the desorption conditions. Studies on vehicular methane or hydrogen gas storage and delivery via adsorbents use the deliverable/usable capacity of the gas in the material- the density of gas in the material at the storage condition minus that at the discharge condition [54 55]- as a performance metric for the material. The deliverable capacity accounts for the residual gas trapped in the material at the discharge pressure, which cannot be delivered. We assumed the deliverable/usable capacity of xenon in the adsorbent is equal to the adsorbed xenon density at the storage pressure because, in space, the discharge pressure corresponds to vacuum. I.e., we assume that the xenon gas adsorbed in the material at the storage pressure $P$ can be fully delivered.

Temperature of 298 K. We took a storage temperature of 298 K, as in Refs. [8, 25]. The performance of adsorbents compared to bulk storage could be improved by lowering the storage temperature, since generally adsorbents will achieve a higher adsorbed xenon density at lower temperatures.

\section{Conclusions and future work}

We formulated a simple mathematical model of an adsorbed xenon propellant storage system, composed of (i) a stress model for the thin-walled, spherical pressure vessel coupled with (ii) a Langmuir adsorption model to describe the adsorbed xenon density in the porous material. We used the model to find the optimum storage pressure that minimizes the mass of the storage materials (composed of (i) the metal comprising the walls of the pressure vessel and (ii) the adsorbent material) required to carry the xenon onboard the spacecraft. We derived eqns. 10 and 11 interpretable expressions for the optimum storage pressure and associated minimum tankage fraction, revealing how properties of the materials (both the metal and the adsorbent) affect the performance of the adsorbed xenon storage system. Fig. 6 compares the performance of several adsorbent materials for Xe propellant storage, with bulk Xe storage as a baseline. 
We conclude that, for the adsorbent materials considered in Fig. 4 the reduction in the mass of the pressure vessel walls, enabled by reduced storage pressures provided by the adsorbents, does not compensate for the increased mass of adsorbent material. That is, an adsorbed Xe storage system does not provide weight savings compared to the bulk Xe storage system. Because the mass of the adsorbent dominates the tankage fraction, the tankage fraction is, to first order approximation, inversely related to the gravimetric saturation loading of xenon in the adsorbent [units: amount of Xe per mass of adsobent]. Our model suggests to, in pursuit of an adsorbent that can outperform the bulk storage system, search for adsorbents with a xenon saturation loading exceeding $94 \mathrm{~mol}$ $\mathrm{Xe} / \mathrm{kg}$ adsorbent.

Ni-MOF-74 and MOF-505 do, however, offer an improved tankage fraction over the traditional adsorbent, activated carbon, which was previously considered for xenon propellant storage [10].

Our model is only a first-order approximation to answer the question of whether nanoporous materials are a worthy pursuit for xenon propellant storage, with the objective of minimizing the mass of the storage materials. We listed and discussed several limitations of our model above. Taken together, these limitations indicate that our mathematical model should be viewed as a Fermi estimate for determining whether adsorbents are worth pursuit for xenon propellant storage.

Future work includes (a) developing a COPV stress model and coupling it with the adsorbent model, (b) considering different tank geometries, and (c) expanding the scope of adsorbent materials considered by e.g., a high-throughout computational screening of materials for xenon propellant storage [56].

\section{Acknowledgements}

N.G., P.K.T, and C.M.S. acknowledge the U.S. Department of Defense (DoD) Defense Threat Reduction Agency (HDTRA-19-31270) for the necessary funding and support. PNNL is operated by Battelle for the U.S. DOE under contract DE-AC05-76RL01830. M.T.H. and S.H. thank the Pete and Rosalie Johnson Internship Program at Oregon State University.

\section{References}

[1] James S Sovey, Vincent K Rawlin, and Michael J Patterson. Ion propulsion development projects in US: Space Electric Rocket Test I to Deep Space 1. Journal of Propulsion and Power, 17(3):517526, 2001.

[2] John R Brophy. NASA's Deep Space 1 ion engine (plenary). Review of Scientific Instruments, 73(2):1071-1078, 2002.

[3] V Rawlin, M Patterson, and R Gruber. Xenon ion propulsion for orbit transfer. In 21st International Electric Propulsion Conference, page 2527, 1990.

[4] JR Beattie, JN Matossian, and R Robson. Status of xenon ion propulsion technology. Journal of Propulsion and Power, 6(2):145-150, 1990. 
[5] Walter Tam, Arthur Jackson, Eiji Nishida, Yukikazu Kasai, Akio Tsujihata, and Kenichi Kajiwara. Design and manufacture of the ets viii xenon tank. In 36th American Institute of Aeronautics and Astronautics/American Society of Mechanical Engineers/Society of Automotive Engineers/American Society for Engineering Education Joint Propulsion Conference \& Exhibit, page 3677, 2000.

[6] JR Beattie, JN Matossian, RL Poeschel, WP Rogers, and RM Martinelli. Xenon ion propulsion subsystem. Journal of Propulsion and Power, 5(4):438-444, 1989.

[7] John Brophy, Michael Marcucci, Jason Gates, Charles Garner, Barry Nakazono, and G Ganapathi. Status of the DAWN ion propulsion system. In 40th AIAA/ASME/SAE/ASEE Joint Propulsion Conference and Exhibit, page 3433, 2004.

[8] John R Brophy, Roy Y Kakuda, James E Polk, John R Anderson, Michael G Marcucci, David Brinza, Michael D Henry, Kenneth K Fujii, Kamesh R Mantha, John F Stocky, James Sovey, Mike Patterson, Vince Rawlin, John Hamley, Tom Bond, Jon Christensen, Hap Cardwell, Gerald Benson, Joe Gallagher, Mike Matranga, and Duff Bushway. Ion propulsion system (NSTAR) DS1 technology validation report. Deep Space 1 Technology Validation Report-Ion Propulsion System (NSTAR), 2000.

[9] Brian Dunbar. Advanced space transportation program fact sheet. National Aeronautics and Space Administration - Marshall Space Flight Center Archives, 12, 2008.

[10] Dwight D Back, Charlie Ramos, and John A Meyer. Low-pressure long-term xenon storage for electric propulsion. NASA, 2001.

[11] Hiroyasu Furukawa, Kyle E Cordova, Michael O'Keeffe, and Omar M Yaghi. The chemistry and applications of metal-organic frameworks. Science, 341(6149), 2013.

[12] Andrew I Cooper. Porous molecular solids and liquids. ACS Central Science, 3(6):544-553, 2017.

[13] Christian S Diercks and Omar M Yaghi. The atom, the molecule, and the covalent organic framework. Science, 355(6328), 2017.

[14] Omar K Farha, Ibrahim Eryazici, Nak Cheon Jeong, Brad G Hauser, Christopher E Wilmer, Amy A Sarjeant, Randall Q Snurr, SonBinh T Nguyen, A "Ozg"ur Yazaydın, and Joseph T Hupp. Metalorganic framework materials with ultrahigh surface areas: is the sky the limit? Journal of the American Chemical Society, 134(36):15016-15021, 2012.

[15] Yanpei Song, Qi Sun, Briana Aguila, and Shengqian Ma. Opportunities of covalent organic frameworks for advanced applications. Advanced Science, 6(2):1801410, 2019.

[16] Alexander Schoedel, Zhe Ji, and Omar M Yaghi. The role of metal-organic frameworks in a carbon-neutral energy cycle. Nature Energy, 1(4):1-13, 2016.

[17] Debasis Banerjee, Cory M Simon, Anna M Plonka, Radha K Motkuri, Jian Liu, Xianyin Chen, Berend Smit, John B Parise, Maciej Haranczyk, and Praveen K Thallapally. Metal-organic framework with optimally selective xenon adsorption and separation. Nature Communications, 7(1):17, 2016.

[18] Debasis Banerjee, Cory M Simon, Sameh K Elsaidi, Maciej Haranczyk, and Praveen K Thallapally. Xenon gas separation and storage using metal-organic frameworks. Chem, 4(3):466-494, 2018. 
[19] Debasis Banerjee, Amy J Cairns, Jian Liu, Radha K Motkuri, Satish K Nune, Carlos A Fernandez, Rajamani Krishna, Denis M Strachan, and Praveen K Thallapally. Potential of metal-organic frameworks for separation of xenon and krypton. Accounts of chemical research, 48(2):211-219, 2015.

[20] Sameh K Elsaidi, Daniele Ongari, Mona H Mohamed, Wenqian Xu, Radha Kishan Motkuri, Maciej Haranczyk, and Praveen K Thallapally. Metal organic frameworks for xenon storage applications. ACS Materials Letters, 2(3):233-238, 2020.

[21] Carl T Herakovich. Thin-walled pressure vessels. In A Concise Introduction to Elastic Solids, pages 77-81. Springer, 2017.

[22] Gerhard Welsch, Rodney Boyer, and EW Collings. Materials properties handbook: titanium alloys. American Society for Metals International, 1993.

[23] Mitsuo Niinomi. Mechanical properties of biomedical titanium alloys. Materials Science and Engineering: A, 243(1-2):231-236, 1998.

[24] Charles W Bert, Earl J Mills, and Walter S Hyler. Mechanical properties of aerospace structural alloys under biaxial-stress conditions. Technical Report TR-66-229, Battelle Memorial Institute Columbus Laboratories, Air Force Materials Laboratory, Wright-Patterson AFB, Ohio, 1966.

[25] Richard P Welle. Propellant storage considerations for electric propulsion. In 22nd International Electric Propulsion Conference, pages 91-107, 1991.

[26] Mark O. McLinden Eric W. Lemmon and Daniel G. Friend. Thermophysical Properties of Fluid Systems" in NIST Chemistry WebBook, NIST Standard Reference Database Number 69. Eds. P.J. Linstrom and W.G. Mallard, National Institute of Standards and Technology, Gaithersburg MD, 20899. https://doi.org/10.18434/T4D303, (retrieved February 5, 2020).

[27] Hans Swenson and Nicholas P Stadie. Langmuir's theory of adsorption: A centennial review. Langmuir, 35(16):5409-5426, 2019.

[28] Kyle J Korman, Gerald E Decker, Michael R Dworzak, Meaghan M Deegan, Alexandra M Antonio, Garrett A Taggart, and Eric D Bloch. Using low-pressure methane adsorption isotherms for higher-throughput screening of methane storage materials. ACS Applied Materials \& Interfaces, 12(36):40318-40327, 2020.

[29] Bardiya Valizadeh, Tu N Nguyen, and Kyriakos C Stylianou. Shape engineering of metal-organic frameworks. Polyhedron, 145:1-15, 2018.

[30] Mirko Kunowsky, Fabián Suárez-García, and Ángel Linares-Solano. Adsorbent density impact on gas storage capacities. Microporous and mesoporous materials, 173:47-52, 2013.

[31] J Dhainaut, C Avci-Camur, J Troyano, A Legrand, J Canivet, I Imaz, D Maspoch, H Reinsch, and D Farrusseng. Systematic study of the impact of MOF densification into tablets on textural and mechanical properties. CrystEngComm, 19(29):4211-4218, 2017. 
[32] Debasis Banerjee, Zhijuan Zhang, Anna M Plonka, Jing Li, and John B Parise. A calcium coordination framework having permanent porosity and high $\mathrm{CO}_{2} / \mathrm{N}_{2}$ selectivity. Crystal Growth \& Design, 12(5):2162-2165, 2012.

[33] Nathaniel L Rosi, Jaheon Kim, Mohamed Eddaoudi, Banglin Chen, Michael O'Keeffe, and Omar M Yaghi. Rod packings and metal-organic frameworks constructed from rod-shaped secondary building units. Journal of the American Chemical Society, 127(5):1504-1518, 2005.

[34] Stephen S-Y Chui, Samuel M-F Lo, Jonathan PH Charmant, A Guy Orpen, and Ian D Williams. A chemically functionalizable nanoporous material $\left[\mathrm{Cu}_{3}(\mathrm{TMA})_{2}\left(\mathrm{H}_{2} \mathrm{O}\right)_{3}\right]_{n}$. Science, 283(5405):11481150, 1999.

[35] Xianyin Chen, Anna M Plonka, Debasis Banerjee, Rajamani Krishna, Herbert T Schaef, Sanjit Ghose, Praveen K Thallapally, and John B Parise. Direct observation of Xe and $\mathrm{Kr}$ adsorption in a Xe-selective microporous metal-organic framework. Journal of the American Chemical Society, 137(22):7007-7010, 2015.

[36] Kunhao Li, David H Olson, Jeong Yong Lee, Wenhua Bi, Ke Wu, Tan Yuen, Qiang Xu, and Jing Li. Multifunctional Microporous MOFs Exhibiting Gas/Hydrocarbon Adsorption Selectivity, Separation Capability and Three-Dimensional Magnetic Ordering. Advanced Functional Materials, 18(15):2205-2214, 2008.

[37] Banglin Chen, Nathan W Ockwig, Andrew R Millward, Damacio S Contreras, and Omar M Yaghi. High $\mathrm{H}_{2}$ adsorption in a microporous metal-organic framework with open metal sites. Angewandte Chemie International Edition, 44(30):4745-4749, 2005.

[38] Xiang Lin, Irvin Telepeni, Alexander J Blake, Anne Dailly, Craig M Brown, Jason M Simmons, Marco Zoppi, Gavin S Walker, K Mark Thomas, Timothy J Mays, Peter Hubberstey, Neil R. Champness, and Martin Schroder. High capacity hydrogen adsorption in Cu (II) tetracarboxylate framework materials: the role of pore size, ligand functionalization, and exposed metal sites. Journal of the American Chemical Society, 131(6):2159-2171, 2009.

[39] Debanjan Chakraborty, Shyamapada Nandi, Rahul Maity, Radha Kishan Motkuri, Kee Sung Han, Sean Collins, Paul Humble, James C. Hayes, Tom K. Woo, Ramanathan Vaidhyanathan, and Praveen K. Thallapally. An ultra-microporous metal-organic framework with exceptional xe capacity. Chemistry - A European Journal, 26(55):12544-12548, September 2020.

[40] Tomokazu Tozawa, James T. A. Jones, Shashikala I. Swamy, Shan Jiang, Dave J. Adams, Stephen Shakespeare, Rob Clowes, Darren Bradshaw, Tom Hasell, Samantha Y. Chong, Chiu Tang, Stephen Thompson, Julia Parker, Abbie Trewin, John Bacsa, Alexandra M. Z. Slawin, Alexander Steiner, and Andrew I. Cooper. Porous organic cages. Nature Materials, 8(12):973-978, October 2009.

[41] Hao Wang, Kexin Yao, Zhijuan Zhang, Jacek Jagiello, Qihan Gong, Yu Han, and Jing Li. The first example of commensurate adsorption of atomic gas in a mof and effective separation of xenon from other noble gases. Chemical Science, 5(2):620-624, 2014. 
[42] John J Perry IV, Stephanie L Teich-McGoldrick, Scott T Meek, Jeffery A Greathouse, Maciej Haranczyk, and Mark D Allendorf. Noble gas adsorption in metal-organic frameworks containing open metal sites. The Journal of Physical Chemistry C, 118(22):11685-11698, 2014.

[43] Linjiang Chen, Paul S. Reiss, Samantha Y. Chong, Daniel Holden, Kim E. Jelfs, Tom Hasell, Marc A. Little, Adam Kewley, Michael E. Briggs, Andrew Stephenson, K. Mark Thomas, Jayne A. Armstrong, Jon Bell, Jose Busto, Raymond Noel, Jian Liu, Denis M. Strachan, Praveen K. Thallapally, and Andrew I. Cooper. Separation of rare gases and chiral molecules by selective binding in porous organic cages. Nature Materials, 13(10):954-960, 2014.

[44] Praveen K Thallapally, Jay W Grate, and Radha Kishan Motkuri. Facile xenon capture and release at room temperature using a metal-organic framework: a comparison with activated charcoal. Chemical Communications, 48(3):347-349, 2012.

[45] AquaCarb and Westates. Westates ${ }^{\circledR}$ coconut shell based granular activated carbon - aquacarb ${ }^{\circledR} 830 \mathrm{c}$, 1230c and 1240c carbons. https://www.evoqua.com/siteassets/documents/products/carbon-resin/wsaq12ds.pdf, 2017.

[46] Scott T Meek, Stephanie L Teich-McGoldrick, John J Perry, Jeffery A Greathouse, and Mark D Allendorf. Effects of polarizability on the adsorption of noble gases at low pressures in monohalogenated isoreticular metal-organic frameworks. The Journal of Physical Chemistry $C$, 116(37):19765-19772, 2012.

[47] David Dubbeldam, Sofía Calero, Donald E. Ellis, and Randall Q. Snurr. RASPA: molecular simulation software for adsorption and diffusion in flexible nanoporous materials. Molecular Simulation, 42(2):81-101, February 2015.

[48] Alauddin Ahmed, Saona Seth, Justin Purewal, Antek G. Wong-Foy, Mike Veenstra, Adam J. Matzger, and Donald J. Siegel. Exceptional hydrogen storage achieved by screening nearly half a million metal-organic frameworks. Nature Communications, 10(1), April 2019.

[49] Christopher E. Wilmer, Michael Leaf, Chang Yeon Lee, Omar K. Farha, Brad G. Hauser, Joseph T. Hupp, and Randall Q. Snurr. Large-scale screening of hypothetical metal-organic frameworks. Nature Chemistry, 4(2):83-89, November 2011.

[50] Colin D Wood, Bien Tan, Abbie Trewin, Fabing Su, Matthew J Rosseinsky, Darren Bradshaw, Yan Sun, Li Zhou, and Andrew I Cooper. Microporous organic polymers for methane storage. Advanced Materials, 20(10):1916-1921, 2008.

[51] Peyman Z Moghadam, Aurelia Li, Seth B Wiggin, Andi Tao, Andrew GP Maloney, Peter A Wood, Suzanna C Ward, and David Fairen-Jimenez. Development of a cambridge structural database subset: a collection of metal-organic frameworks for past, present, and future. Chemistry of Materials, 29(7):2618-2625, 2017.

[52] Michael Kezirian, Kevin Johnson, and Stuart Phoenix. Composite overwrapped pressure vessels (COPV): Flight rationale for the Space Shuttle Program. In American Institute of Aeronautics and Astronautics Space 2011 Conference \& Exposition, page 7363, 2011. 
[53] Wulf Radtke. Manufacturing of advanced titanium (lined) propellant tanks and high pressure vessels. Proceedings of the 4th International Spacecraft Propulsion Conference (ESA SP-555), 2004.

[54] Paula García-Holley, Benjamin Schweitzer, Timur Islamoglu, Yangyang Liu, Lu Lin, Stephanie Rodriguez, Mitchell H. Weston, Joseph T. Hupp, Diego A. Gómez-Gualdrón, Taner Yildirim, and Omar K. Farha. Benchmark study of hydrogen storage in metal-organic frameworks under temperature and pressure swing conditions. ACS Energy Letters, 3(3):748-754, March 2018.

[55] Jarad A Mason, Mike Veenstra, and Jeffrey R Long. Evaluating metal-organic frameworks for natural gas storage. Chemical Science, 5(1):32-51, 2014.

[56] Arni Sturluson, Melanie T Huynh, Alec R Kaija, Caleb Laird, Sunghyun Yoon, Feier Hou, Zhenxing Feng, Christopher E Wilmer, Yamil J Colón, Yongchul G Chung, Dan Siderius, and Cory Simon. The role of molecular modelling and simulation in the discovery and deployment of metalorganic frameworks for gas storage and separation. Molecular Simulation, 45(14-15):1082-1121, 2019. 